\title{
¿EXISTIO LA CULTURA LOMA SAN GABRIEL? EL CASO DE HERVIDEROS, DURANGO
}

\section{MARIE-AREti Hers}

La escasez de trabajos arqueológicos en los confines septentrionales de Mesoamérica es particularmente aguda cuando se trata del actual estado de Durango. Por esa razón me permito presentar aquí algunas informaciones nuevas aunque notablemente incompletas sobre un sitio importante, ubicado en la Sierra Madre Occidental durangueña. Se trata de Hervideros que, por su ubicación en el corazón del territorio de lo que se ha llamado cultura Loma San Gabriel, nos llevará a cuestionar la existencia misma de esa cultura como entidad espacio-temporal distinta de la cultura Chalchihuites.

La idea de una cultura Loma San Gabriel considerada como semicivilizada, parcialmente mesoamericana, empezó a germinar en los años 30 , cuando Alden Mason realizó su recorrido desde la zona de Chalchihuites en el noroeste de Zacatecas hasta Zape en el norte de Durango. ${ }^{1}$ En una apreciación intuitiva y apresurada sentenció que a medida que uno se dirigiese hacia el norte en el territorio de la cultura Chalchihuites se encontraria con vestigios de una ocupación prehispánica cada vez menos civilizada, más simple y primitiva. Ese juicio, sin embargo, no lo llevó a diferenciar culturalmente la amplia región que atravesó y en la cual reconoció la misma cultura Chalchihuites que se había empezado a conocer en diversos sitios zacatecanos.

Si hubiese visitado personalmente las ruinas de Hervideros es probable que hubiese matizado su apreciación sobre el desarrollo cultural alcanzado en esos confines mesoamericanos, apreciación que influyó.considerablemente en las interpretaciones posteriores, hasta el grado de que el supuesto empobrecimiento hacia el norte llegó a ser identificado como una cultura distinta a la Chalchihuites, y a la cual se le dio el nombre de Loma San Gabriel, según el topónimo de un sitio al extremo norte de Durango.

Pero el primer estudio arqueológico realizado en Hervideros fue exce-

1 Alden Mason. "Late Archaeological Sites in Durango, México, from Chalchihuites to Zape", Twentyfifth Anniversary Studies, vol. 1, pp. 127-146, Philadelphia Anthropological Society, Philadelphia, 1937: pp. 137-138, figura 2b-1a3. 
sivamente informal. Cuando Alden Mason llegó a la estación ferrocarrilera del mismo nombre, se fue en pos de los vestigios del Arcaico que le interesaban primordialmente y se limitó a mandar a uno de sus acompañantes escalar el cerro y excavar entre las ruinas que, según le habían informado, recubrian toda la cumbre. Se enteró así de que entre los vestigios visibles en la superficie, destacaba por su inesperada calidad el conjunto de construcciones que ocupaba la parte más alta del cerro. ${ }^{2}$

El sitio de Hervideros ya era conocido en ese entonces por haber sido objeto de algunos saqueos. Estos habían proporcionado materiales, entre los cuales sobresalen una vistosa vasija trípode con decoración grabada del tipo llamado ahora Michilia red-filled engraved, característico de la cultura Chalchihuites, y objetos de cobre, como una orejera, de la cual nos ocuparemos más adelante. ${ }^{3}$ El refinamiento de la arquitectura y la calidad de los objetos encontrados llamaron la atención de Alden Mason. Sin embargo, ni estos datos ni la ubicación muy septentrional del sitio lo llevaron a reconsiderar su interpretación general del desarrollo cultural alcanzado en Durango durante la época prehispánica. ${ }^{4}$

Veinte años después, el sitio fue visitado de nuevo por Glen Cole, miembro del equipo encabezado por J. Charles Kelley, quien por esas fechas llevaba a cabo excavaciones arqueológicas en Schroeder-Ferrería en el valle de Guadiana. La visita al sitio se enmarcaba en una serie de recorridos preliminares destinados a localizar y a fechar tentativamente vestigios muy variados, desde restos del Arcaico hasta sitios mesoamericanos. Por lo tanto, el examen del lugar no estaba destinado ni a analizar

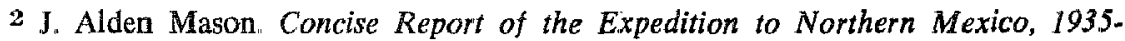
1936, under the Auspices of the American Philosophical Society (ARCHIVO TÉCNICO, vol 179), Departamento de Monumentos Prehispánicos, Instituto Nacional de Antropología e Historia, ms.

3 J. Alden Mason $O p$. Cit., 1937, p. 138: además de los objetos mencionados, se anota la presencia de ornamentos en concha con círculos grabados, cuentas de concha y de piedra, sonajas de cobre, una figura humana delicadamente esculpida en hueso, malacates cónicos biocónicos, una figura en barro negro, cerámica decorada en rojo sobre crema, utillaje en obsidiana y hachas en piedra.

4 El cerro Hervideros se encuentra a $105^{\circ} 28^{\prime}$ de longitud oeste y $25^{\circ} 09^{\prime}$ de latitud norte y sus coordenadas de cuadrícula son DT 5328 14. Se ubica a la mitad del camino entre las poblaciones actuales de Los Herrera y Atotonilco y a una docena de kilómetros al noreste de Santiago Papasquiaro. A vuelo de pájaro, una distancia de unos $150 \mathrm{~km}$ lo separa del único sitio mesoamericano abierto excavado hasta ahora en Durango, el de Schroeder-Ferrería en el valle de Guadiana a las orillas de la ciudad de Durango y a $245 \mathrm{~km}$ de la población de Chalchihuites donde Alden Mason empezó su recorrido, y junto a la cual Manuel Gamio había excavado el sitio de Alta Vista a principios del siglo. 
sistemáticamente el patrón de asentamiento en el cual se inscribía el sitio ni a detallar sus vestigios arquitectónicos. Es por esa razón que se repite en el informe de esa visita lo apuntado anteriormente por Alden Mason acerca del conjunto arquitectónico en la parte más alta, y se dedica la estancia de varios días en recoger materiales con el fin de compararlos con los del valle de Guadiana, para los cuales se estaba estableciendo un cuadro cronológico $0^{5}$ Se encontraron así evidencias de una ocupación del lugar por 10 menos entre 550 y 1150 d.C. ${ }^{6}$

Al mismo tiempo, pero separadamente, Richard Brooks emprendía un recorrido de superficie aguas abajo a lo largo del río Ramos. ${ }^{7}$ La zona que recorrió se encuentra solamente a $40 \mathrm{~km}$ a vuelo de pájato del Cerro Hervideros, pero está separada por un macizo barrancoso. Éste no constituia un obstáculo importante para las comunicaciones pedestres entre antiguos pobladores serranos y ha de representar menos de un día de caminata, pero impide el paso vehicular entre las dos partes y, por lo tanto,

5 J. Charles Kelley. Informe de recorridos efectuados en 1956 en el estado de Durango (Archivo técnico, vol. 51), Departamento de Monumentos Prehispánicos, Instituto Nacional de Antropología e Historia, ms.: el sitio aparece con la sigla de LSQL-54. Entre los objetos en piedra recolectados figuran numerosas manos y metates, tejolotes, utillaje lasqueado, bruñidores, cuentas en piedra y en hueso y cruces en obsidiana. Entre los tepalcates, destacan tipos pintados de las fases Ayala (550-700) y Tunal $(950-1150)$, además de un fragmento del tipo Guasave-red-Rim procedente de la región sinaloense.

${ }^{6}$ Recientemente, $\mathbf{J}$. Charles Kelley ha propuesto diversas opciones para modificar la cronología que había establecido para el valle de Guadiana y adecuarla a la que definió posteriormente para lo que llama la rama Súchil y en particular para el sitio de Alta Vista Sin embargo, hasta no disponer de nuevas fechas absolutas para asentamientos mesoamericanos en Durango, no me parece prudente descartar, como lo propone, la serie de fechas C14 obtenida en sus excavaciones de SchroederFerrería, internamente coherente, para apoyar interpretaciones estratigráficas en Alta Vista y otros sitios del Alto Súchil: "The Chronology of the Chalchihuites Culture", pp. 269-288, in Michael S. Foster and Phil C. Weigand, eds., The Archaelogy of West and Northwest Mesoamerica, Westview Press, Boulder and London, 1985. Por otra parte, hay que recalcar que hasta ahora no se dispone de datos suficientes para precisar desde cuándo se establecieron poblaciones mesoamericanas en Durango y, por lo tanto, el siglo sexto propuesto por J. Charles Kelley es solamente una fecha inicial tentativa.

7 Richard Brooks. Informe de recorrido en la Mesa Central del Estado de Durango, mayo de 1956 (Archivo Técnico, vol. 55), Departamento de Monumentos Prehispánicos, Instituto Nacional de Antropología e Historia, ms. y "A Loma San Gabriel/Chalchihuites Cultural Manifestation in the Río Ramos Región, Durango, México", pp. 83-95 en Carroll L. Riley and Basil C. Hedrick, eds., Across the Chichimec Sea; papers in honor of J. Charles Kelley, Southern Illinois University Press, Carbondale and Edwardsville, Feffer and Simons, Inc. London and Amsterdam, 1978. 
Richard Brooks no pudo apreciar cabalmente el entorno de la zona que recorrió. En su exploración preliminar, localizó varios sitios, algunos mesoamericanos similares a las pequeñas poblaciones ya conocidas en la zona de Zape, y levantó planos esquemáticos de éstos. La falta de comunicación señalada entre las zonas del río Ramos y de sus afluentes aguas arriba no le permitió percatarse del contraste que existía entre los asentamientos aldeanos que estudió y el sitio mayor relativamente cercano de Hervideros.

En esas circunstancias particulares, se entiende cómo las escasas informaciones reunidas acerca del sitio que nos ocupa no aportaron sustancialmente nada nuevo, ni influyeron en la definición de la cultura Loma San Gabriel que J. Charles Kelley empezaba a elaborar por ese entonces, con base en los diversos recorridos que se habian realizado en Durango desde los trabajos de Alden Mason y los de Donald Brand en los alrededores de Zape en 1936, hasta los de su equipo a lo largo de los años 50 y $60 .^{8}$

J. Charles Kelley diferenció la cultura Chalchihuites de la cultura Loma San Gabriel por su distribución espacio-temporal considerando que ésta se había desarrollado principalmente al norte del territorio de la primera y que tuvo una duración mucho mayor. La cultura Loma San Gabriel fue definida así como un desarrollo local milenario que habría empezado mucho antes de la llegada de los pobladores mesoamericanos en el septentrión y que habría sobrevivido a la contracción de la frontera mesoamericana en el Postclásico, subsistiendo en la cultura de los tepehuanes.

Esa definición fue sistematizada posteriormente por Michael Foster con base en los mismos datos arqueológicos y sin nuevos trabajos de campo. Coincide sustancialmente con la definición propuesta por J. Charles Kelley, pero amplía hacia el sur el territorio atribuido a la cultura Loma San Gabriel, hasta el Alto-Chapalanga y hasta el valle de Malpa-

8 Donald D. Brand. "Notes on the Geography and Archaeology of Zape, Durango", pp. 75-106, en Donald D. Brand and Fred E. Harvey, eds., So Live the Works of Men; Seventieth Anniversany Volume Honoring Edgar Lee Hewiti, University of New Mexico, Albuquerque, 1939; J. Alden Mason, Op. cil., 1937; J.

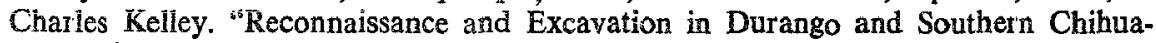
hua, México", Yearbook of the American Philosophical Society, pp. 172-176, American Philosophical Society, Philadelphia, 1953; "Archaelogy of the Northern Frontier: Zacatecas and Durango", pp. 95-110, en Gordon Eckholm and Ignacio Bernal, eds., Handbook of Middle American Indians, vol. 11, pp. 768-801, University of Texas Press, Austin, 1971; J. Charles Kelley and Ellen Abbott. "The Cultural Sequence on the North Central Frontier of Mesoamerica", Actas y Memorias del XXXVI Congreso Internacional de Americanistas, (Madrid, 1964), t. 1 pp. 324344, Sevilla, 1966. 
so. Hace coincidir así su distribución espacial con la de la cultura Chalchihuites. ${ }^{9}$

En esa óptica, la cultura Chalchihuites es considerada como el fruto de una expansión mesoamericana hacia el norte durante el primer milenio de nuestra era, mientras que la cultura Loma San Gabriel sería el producto de un desarrollo local desde el Arcaico y hasta la llegada de los españoles. Así, desde el Arcaico con su facies local del Complejo Caracoles, los habitantes de los contrafuertes orientales de la Sierra Madre Occidental habrían evolucionado paulatinamente hasta adoptar la agricultura y la consecuente vida sedentaria en los últimos siglos antes de nuestra era. Sin embargo, de esa evolución milenaria, no se ofrecen más testimonios que ciertas afinidades formales en la lítica.

Cuando al principio de nuestra era, poblaciones mesoamericanas migran hasta esos confines y desarrollan la cultura Chalchihuites, entran en contacto con los autóctonos de la cultura Loma San Gabriel. Estos constituyeron la base rural y aldeana sobre la cual se impusieron los recién llegados, establecidos en sitios mayores. Los escasos datos cronológicos de que se dispone pertenecen a esa época.

Las poblaciones locales adoptan ciertos rasgos mesoamericanos pero preservan su identidad propia, de modo que, al retiro de las poblaciones Chalchihuites hacia el final del primer milenio, prosiguen su propia evolución que desembocó en la cultura de los tepehuanes de los tiempos coloniales. Esa continuidad ha sido postulada por Carroll L. Riley y Howard D. Winters ${ }^{10}$ pero negada por Donald Brand al comparar los asentamientos tepehuanes con los prehispánicos en los alrededores de Zape. ${ }^{11}$

Lo cierto es que la ocupación de la Sierra Madre Occidental y sus contrafuertes orientales durante los últimos siglos antes de la llegada de los españoles no está documentada arqueológicamente, salvo acaso por las excavaciones en el sitio de Weicker. Se presenta generalmente este sitio como típico de la cultura Loma San Gabriel, pero es aparentemente más

- Michael Foster. Loma San Gabriel: A Prehistoric Culture of Northwest Mexi$c o, P h, D$. dissertation, University of Colorado, Boulder, ms.; "Loma San Gabriel; una cultura del Noreste de Mesoamérica", pp. 175-182, en Rutas de Intercambio en Mesoamérica y Norte de México, XVI Mesa redonda (Saltillo, Coahuila, 1979), Sociedad Mexicana de Antropología, Saltillo, 1980; "The Loma San Gabriel Occupation of Zacatecas and Durango, México", pp. 327-352, in Michael S. Foster and Phil C. Weigand, eds., Op. cit., 1985.

10 Carroll L. Riley and Howard D. Winters. "The Prehistoric Tepehuan of Northern Mexico", Southwestern Journal of Anthropology, t. 19-2, pp. 177-185, Albuquerque, 1963.

11 Donald D. Brand. Op. cit., 1939. 
tardío que todos los sitios conocidos y atribuidos a la cultura Chalchihuites o a la Loma San Gabriel. Se diferencia de ellos no solamente por su ubicación en tierras más altas sino también por sus materiales y sus vestigios arquitectónicos. ${ }^{12}$

Al finalizar los escasos datos cronológicos disponibles para los sitios presuntamente Loma San Gabriel, la evolución prácticamente ahistórica de esa cultura a través de varios milenios no se ve confirmada, sino que, al contrario, todo parece indicar que los vestigios considerados bajo esa denominación son contemporáneos de la cultura Chalchihuites, o sea de los nueve primeros siglos de nuestra era para la parte zacatecana y hasta el siglo XIII para la parte durangueña. ${ }^{13}$

Por lo tanto, si la distribución en el tiempo y en el espacio de esas dos culturas coincide en gran medida, la distinción que se ha querido ver entre ellas corresponde ante todo a las diferencias que marcan las jerarquías entre los sitios. Por un lado, se encuentran las poblaciones principales y los pueblos circundantes, para los cuales, por cierto, se han realizado recorridos sistemáticos y la mayoría de las excavaciones. Por otro lado, se identifica como sitios de la cultura Loma San Gabriel a la mayor parte de los asentamientos que se reducen a modestas aldeas, y le son atribuidos a dicha cultura todos los rasgos de simplicidad y primitivismo que se pueden reconocer con base en estudios preliminares de superficie. ${ }^{14}$

12 J. Charles Kelley. Op. cit., 1953; Michael Foster. "The Weicker Site: a Loma San Gabriel Hamlet in Durango, Mexico", Journal of Field Archaeology, in press.

13 Notemos al respecto que la cerámica Loma San Gabriel no puede ser debidamente comparada con la Chalchihuites. En primer lugar porque la predominancia de los tipos domésticos sobre los decorados que se considera propia de una cultura primitiva, no es significativa en sí, sino que es de esperarse en asentamientos aldeanos y entre colecciones recolectadas en la superficie. Además, hasta ahora no se dispone de un estudio de la cerámica doméstica Chalchihuites, sino sólo de la decorada, mientras que en las colecciones Loma San Gabriel, las vasijas decoradas son consideradas como copias o adquisiciones directas de vasijas Chalchihuites. Finalmente, los tipos de decoración que se reportan entre las yasijas domésticas Loma San Gabriel, como son la superficie cepillada o con impresión de uñas, se encuentran también en los sitios considerados como plenamente Chalchihuites.

14 Por cierto, en la Cueva de los Muertos Chiquitos de ocupación Loma San Gabriel y en donde se hicieron breves excavaciones, se encontraron en el mobiliario funerario de infantes ornamentos de turquesa que contradicen el juicio de pobreza en la cultura material que se ha formulado fundándose en colecciones de superficie. Los criterios de simplicidad y primitivismo son determinantes en el estudio realizado por Ellen Abbott de lo que se consideraba como una zona fronteriza entre la cultura Chalchihuites y la Loma San Gabriel durante los primeros siglos de nuestra era. Esa zona se ubica en el Alto Súchil, en el límite entre los estados actuales de Zacatecas y Durango; "Gualterio Abajo: Early Mesoamerican Settlement on the Northwestern Frontier", vol. 1, pp. 41-50, en Las fronteras de Mesoamérica, XIV 
¿Por qué en este caso se ha recurrido a la arriesgada hipótesis de una diferencia a la vez cultural y étnica para interpretar una distancia, por lo demás muy común en cualquiera cultura entre los asentamientos principales y las aldeas? ¿Cómo se ha llegado, en el caso por ejemplo del valle de Guadiana, a suponer que los sitios más grandes ubicados en las lomas que dominan el llano habían sido poblados por mesoamericanos de cultura Chalchihuites, mientras que los aldeanos dispersos al borde de los cultivos habrían sido autóctonos semi-bárbaros parcialmente aculturados y sosteniendo con su labor a los intrusos mesoamericanos más civilizados?

A mi juicio, esa interpretación fue formulada así porque nos encontramos en los confines de Mesoamérica, en los cuales muchos de los elementos mesoamericanos tienen un cariz peculiar que desorientan aún ahora a los estudiosos. Es particularmente representativo al respecto las ambigüedades con las cuales se han abordado las notables singularidades de la arquitectura local.

Pero además, la cultura Chalchihuites presenta otra singularidad, fruto de su carácter fronterizo, que la distingue de las otras culturas mesoamericanas del Clásico. La relativa homogeneidad de los vestigios materiales a lo largo de un territorio en forma de una tira alargada de unos $600 \mathrm{~km}$ contrasta con las variaciones importantes en la organización socio-política que se ve reflejada en los diferentes patrones de asentamientos.

En efecto, se alternan zonas adentro de las cuales se encuentran solamente poblaciones modestas que parecen haberse mantenido fuera del control de algún centro rector y zonas en las cuales se reconoce una clara jerarquía entre los sitios. Sin recurrir a diferencias étnicas y cronológicas aún no documentadas arqueológicamente, se pueden explicar esas variaciones por el papel fundamental que ha tenido el problema de los enfrentamientos bélicos en el desarrollo de jerarquías socio-políticas entre los fronterizos Chalchihuites.

En efecto, recordemos que la presencia mesoamericana en esos confines ha sido el fruto de un movimiento migratorio intruso en territorios de poblaciones nómadas. A juzgar por la naturaleza y la importancia de los diversos sistemas defensivos implementados a lo largo de la larga tira ya mencionada, esa intrusión originó un conflicto latente entre los agricultores sedentarios que vinieron a colonizar esas tierras y los cazadores recolectores que circulaban en ellas. Con el transcurso del tiempo, el enfrentamiento pasó quizás a un segundo plano para dejár lugar a querellas

Mesa Redonda, (Tegucigalpa, 1975), Sociedad Mexicana de Antropología, México, 1976. 
internas entre mesoamericanos, pero es evidente que la región nunca llegó a pacificarse porque nunca se abandonaron las incomodidades impuestas por los sistemas defensivos. De este modo, el desarrollo de poblaciones mayores y por ende de una jerarquización social no estuvo condicionado solamente por las inevitables restricciones impuestas por el medio ambiente a la subsistencia, sino también por las posibilidades que ofrecían cada uno de los parajes para organizar las defensas.

Así, las zonas en donde los aldeanos podían aprovechar el relieve para asegurar ellos mismos su protección, corresponderían a lo que se ha llamado la cultura San Gabriel. Mientras que cuando los productores tuvieron que recurrir a guerreros que los protegieran y por ende los dominaran, se dieron las circunstancias favorables para una gran diferenciación entre los asentamientos, como es el caso del valle de Malpaso dominado por la fortaleza de La Quemada. Una situación intermedia correspondería a los centros rectores regionales en los cuales se agrupaba, por razones de seguridad, una población mayoritariamente agrícola, tal como parece ser el caso de un gran número de sitios Chalchihuites como Cerro Montedehuma, Schroeder-Ferrería y Hervideros, por ejemplo.

Es significativo el hecho de que los autores que más han insistido en reconocer una cultura Loma San Gabriel distinta de la Chalchihuites han dado muy poca importancia a los diversos sistemas defensivos. Mientras que los consideraron como factor determinante en el patrón de asentamiento no reconocen tal diferenciación cultural. Así, Richard Brooks obvia la distinción al referirse a las aldeas defensivas del centro y norte de Durango con la fórmula ambigüa de "Loma San Gabriel/Chalchihuites". Tiempo atrás, Donald Brand no dudaba en ubicar los asentamientos defensivos de la zona Zape en la misma entidad cultural que la de la de los sitios Chalchihuites conocidos entonces como Alta Vista o La Quemada.

Personalmente, he trabajado en el Alto Chapalagana, que podría ser considerado parte del territorio de la cultura Loma San Gabriel por la modestia de sus asentamientos y el mobiliario recolectado en superfície. Sin embargo, cuando se realizaron excavaciones, la zona reveló pertenecer plenamente a la cultura Chalchihuites. ${ }^{15}$ Ahora, con Hervideros, tratare-

15 Se trata de la zona de Huejuquilla el Alto, en el extremo noreste de Jalisco y el oeste zacatecano, y del sitio excavado del Cerro del Huistle: Marie-Areti Hers et Claudine Deltour-Levie. "Dix ans de recherches archéologiques belges dans la Sierra del Nayar (Mexique)", Bulletin des Musées Royaux d'Art et d'Histoire, t. 56-1, pp. 105-117, Musées Royaux d'Art et d'Histoire, Bruxelles, 1985, y Marie- 
mos el caso de un sitio que por su ubicación septentrional ha sido considerado como perteneciente a la cultura Loma San Gabriel. Como veremos, sin embargo, un examen aun muy superficial del lugar permite descartar tal identificación y, al contrario, reconocerlo como un típico centro regional rector Chalchihuites. ${ }^{16}$

En cuanto a los contrastes en la organización socio-política que se advierten en las diferentes zonas del territorio de la cultura Chalchihuites y que parece ser el único sustento firme para concebir una cultura Loma San Gabriel distinta, es necesario matizar considerablemente. Los aldeanos conformaban la gran mayoría de la población de esos confines y por su patrón de asentamientos aparentan haber tenido una organización relativamente igualitaria, en comparación con los pobladores de las zonas dominadas por un sitio rector que habrían sido más claramente estratificados. Sin embargo, la situación parece haber sido más compleja. Así, por ejemplo, excavaciones en sitios supuestamente Loma San Gabriel, como el del Cerro del Huistle (sitio menor de $2 \mathrm{ha}$., en el alto Chapalagana) o las mencionadas en la cueva de los Muertos Chiquitos, han revelado el uso para ciertos infantes de un mobiliario funerario rico en turquesa y otros materiales preciosos que podría ser considerado como el testimonio de unas diferencias sociales heredadas. Mientras que en sitios rectores de la importancia de Cerro Montedehuma, por ejemplo, no se reconocen entre los vestigios de construcciones habitacionales diferencias notables entre las casas del común de la población y las de los dirigentes. Al contrario, los restos visibles en la superficie resaltan por su modestia homogénea, que contrasta con la calidad de los espacios ceremoniales.

Hay que advertir por lo tanto que mientras no se disponga de las excavaciones adecuadas y suficientemente numerosas a lo largo de todo el territorio de la cultura Chalchihuites, no se podrá resolver satisfactoriamente el punto central en que se basa la proposición de distinguir dos

Areti Hers. Los toltecas en tierras chichimecas, (Cuadernos de Historia del Arte, 35), Instituto de Investigaciones Estéticas, UNAM, 1989.

16 Realizé una visita de tres días en abril de 1987 en Cerro Hervideros en compañía de la arq. Enriqueta M. Olguín. Correspondió a una de las etapas de un breve recorrido por diversas partes del territorio Chalchihuites patrocinado por el Proyecto Sierra del Nayar de la Misión Arqueológica Belga para establecer comparaciones entre los vestigios arquitectónicos de un muestreo mínimo de sitios y los que hemos estudiado ampliamente en la zona de Huejuquilla: Marie-Areti Hers. "Aperçu de l'architecture Chalchihuites", en Claudine Deltour-Levie. ed., L'architecture des villages préhispaniques dans la Sierra del Nayar, (Publications d'Histoire de l'Art et d'Archéologie de l'Université Catholique de Louvain, t. LX-LXI), Université Catholique de Louvain, Louvain, sous presse. 
culturas distintas, y que consiste en esas diferencias en la organización socio-política a través del territorio Chalchihuites y en las sucesivas etapas de su desarrollo.

Mientras no se logren esos avances en los trabajos arqueológicos, el concepto de una cultura Loma San Gabriel autónoma me parece ser heurísticamente inadecuado, no solamente por representar una solución excesivamente simplificadora, sino por encubrir inútilmente una carencia considerable de datos. Del mismo modo he rechazado, en otros estudios, las divisiones arbitrarias con las cuales se han subdividido en una serie de "culturas cerámicas" lo que se llamaba antes lato sensu cultura Chalchihuites, ${ }^{17}$ y he propuesto condicionar la definición de divisiones espacio-temporales pertinentes para un desarrollo milenario sobre un territorio considerable a la adquisición de un mínimo de informaciones confiables al respecto. Los nuevos datos sobre Hervideros que presento a continuación pretenden ser una modesta contribución en este sentido y un intento de analizar el espacio construido como un espejo del tejido social que lo creó.

El Cerro Hervideros se yergue en la cercanía de Santiago Papasquiaro, en la confluencia del río Tepehuanes, que corre de norte a sur, y el Santiago, que va del sur a norte, aguas arriba de la población actual de Atotonilco y sobre la ribera derecha del río Tepehuanes. Debe su nombre a fuentes de agua hirviente que brotan al pie de su vertiente norte. Ambos ríos riegan valles relativamente anchos y fértiles.

Son escasas las informaciones que se tienen de los otros asentamientos mesoamericanos que se encuentran en esos valles. ${ }^{18}$ Pero al observar el paisaje desde la cumbre de Hervideros se nota que el cerro goza de una posición privilegiada, no solamente por encontrarse en medio de tierras fértiles, junto a aguas termales y al borde de un río perenne, sino también por ofrecer los mejores dispositivos naturales apropiados para la defensa.

El cerro en sí no es una atalaya inexpugnable, porque no todas sus vertientes son abruptas, pero ofrece diversas ventajas estratégicas. En primer lugar, aislado en medio de los dos valles convergentes, ofrece un oportuno puesto de observación en todas las direcciones. Además, su

17 Marie-Areti Hers, Op. cit., 1989.

18 En las inmediaciones de la población actual de Atotonilco, Glen Cole reporta la presencia de otros sitios (LSQL-61 y 62) que muestran en la superficie vestigios arquitectónicos y cerámica similares a los de Hervideros: Informe... citado en nota 5. 


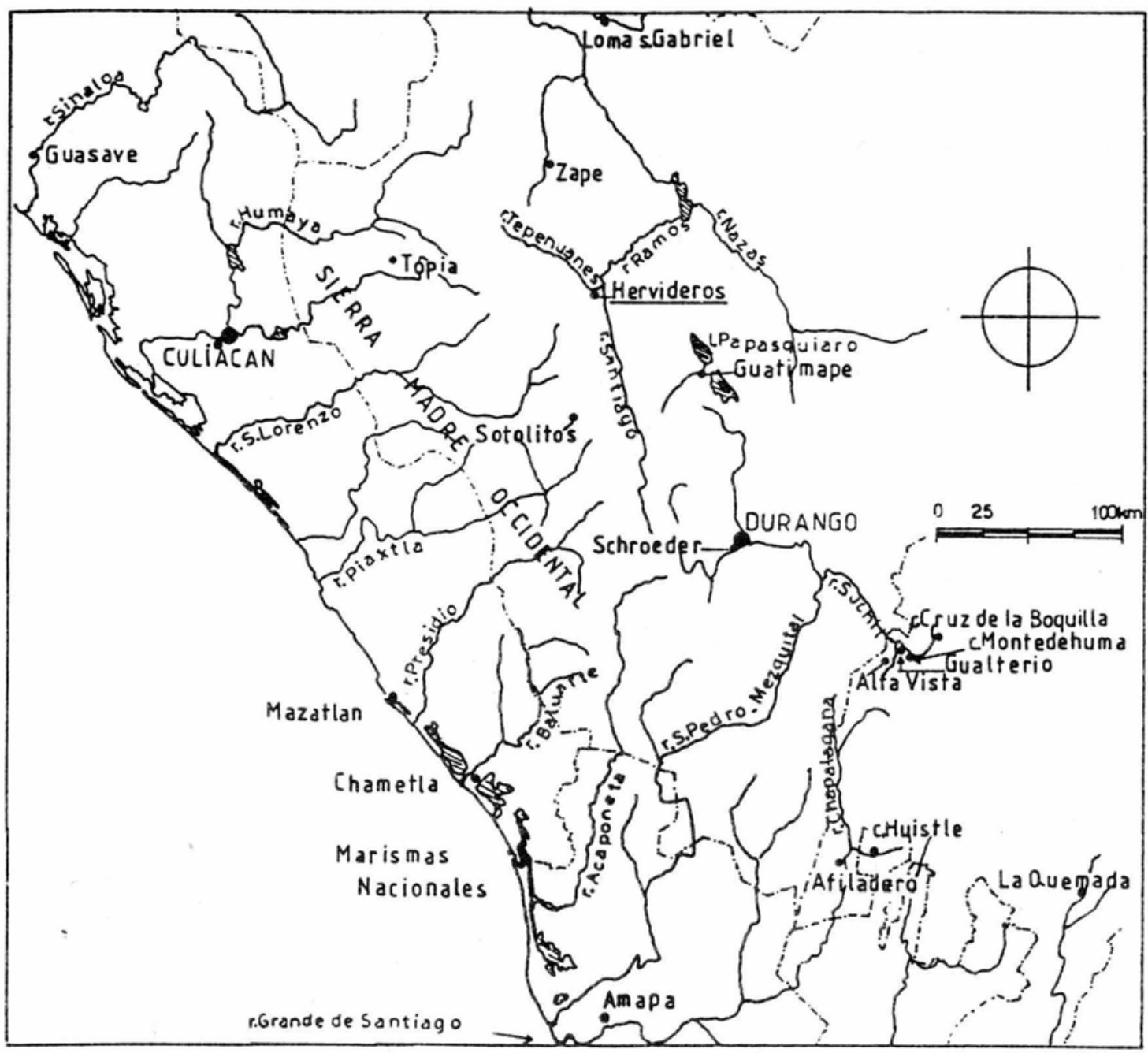

1. Ubicación de los sitios arqueológicos mencionados. 
DOI: http://dx.doi.org/10.22201/iie.18703062e.1989.60.1533
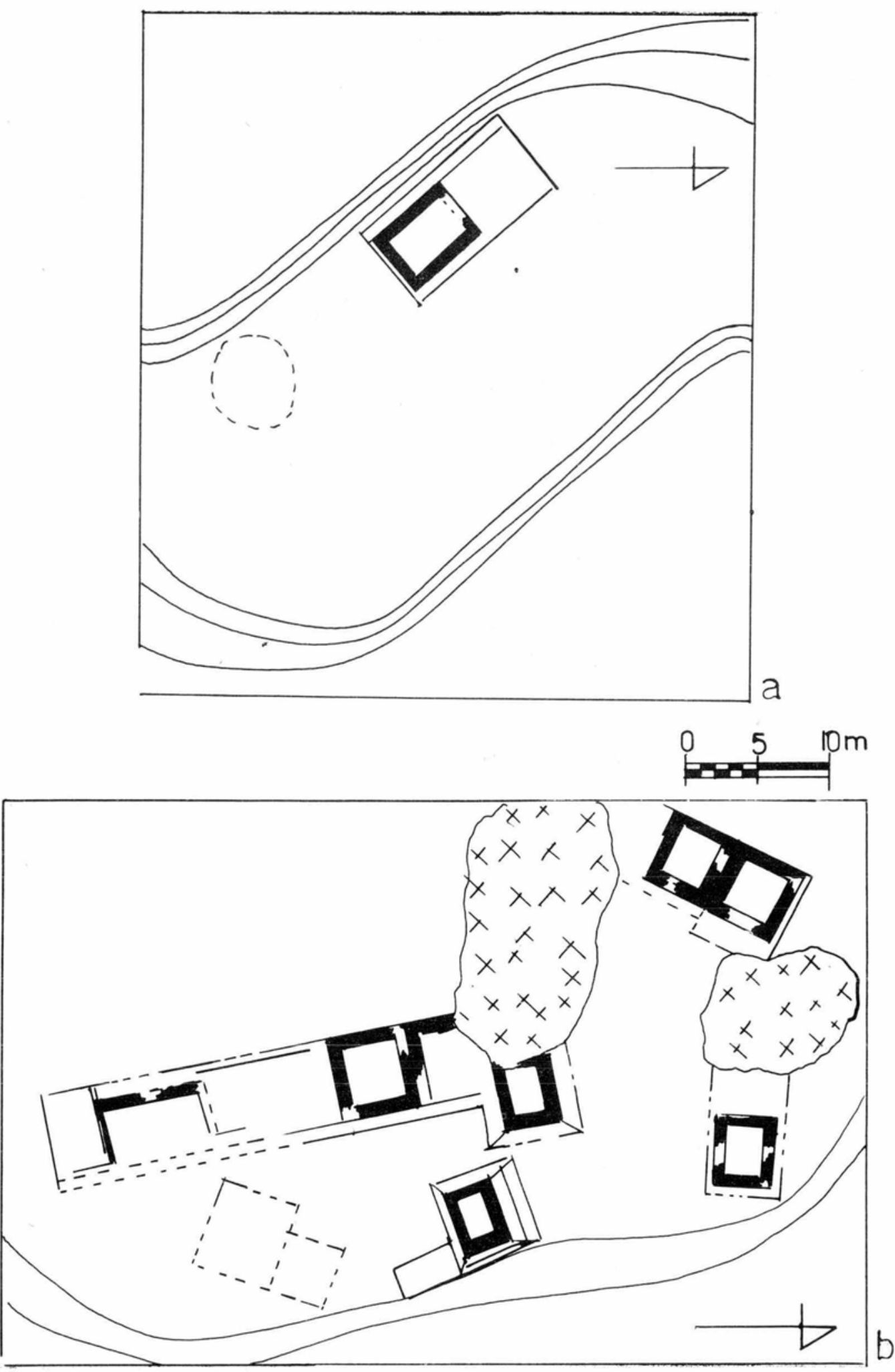

2. Hervideros: a-conjunto 1 ; b-conjunto 2 . 
DOI: http://dx.doi.org/10.22201/iie.18703062e.1989.60.1533
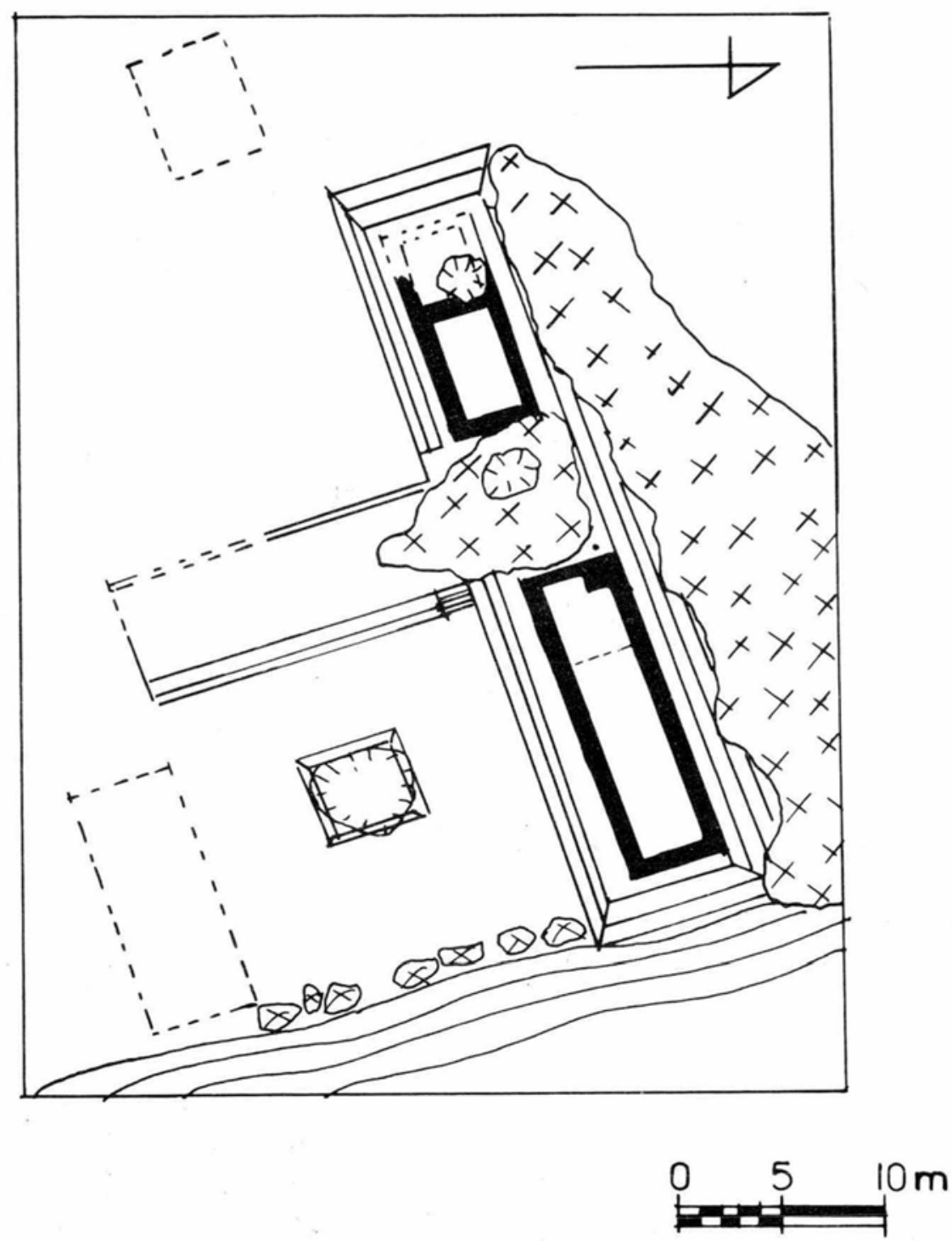

3. Hervideros: conjunto 3. 


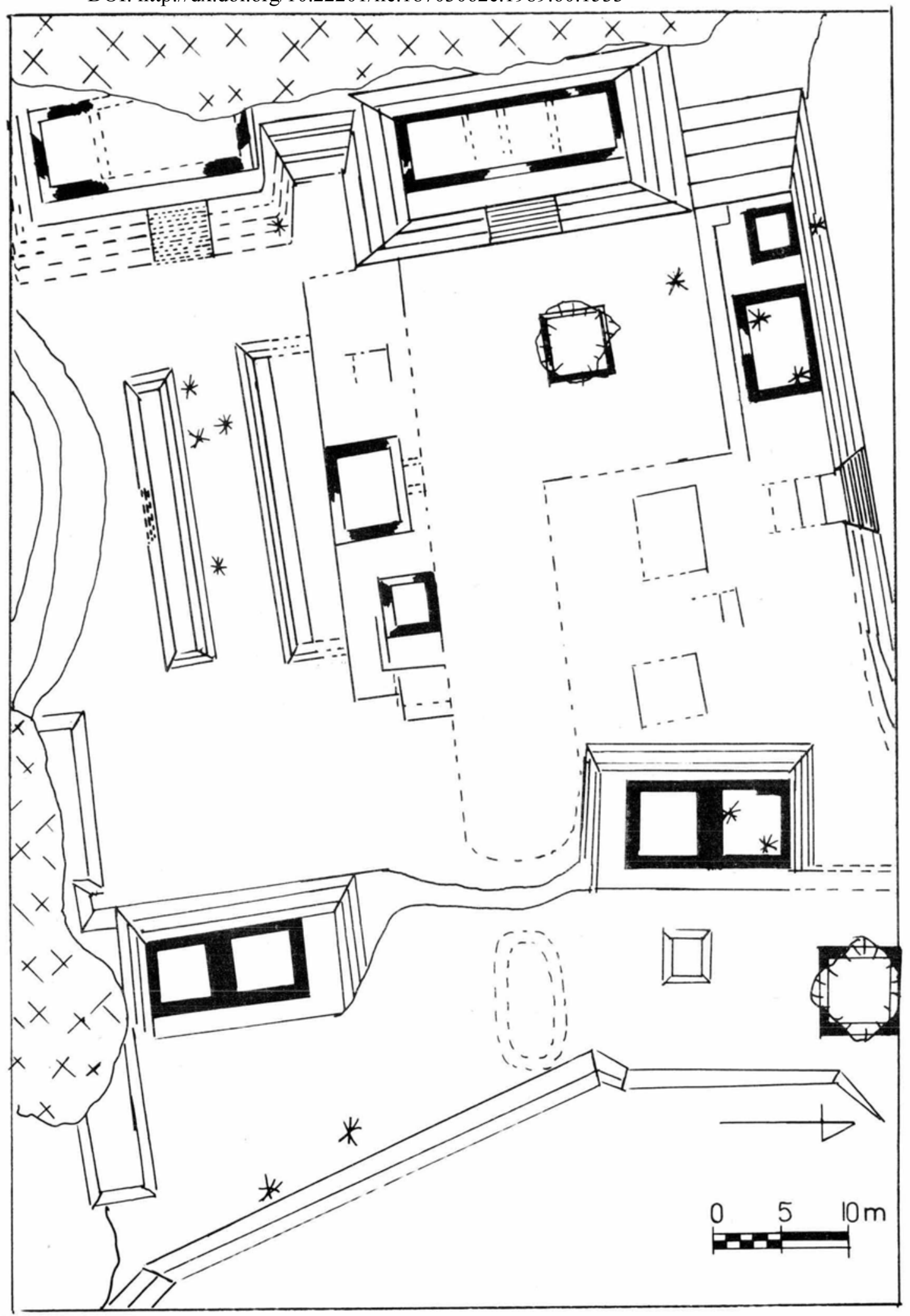

4. Hervideros: conjunto 4. 
DOI: http://dx.doi.org/10.22201/iie.18703062e.1989.60.1533
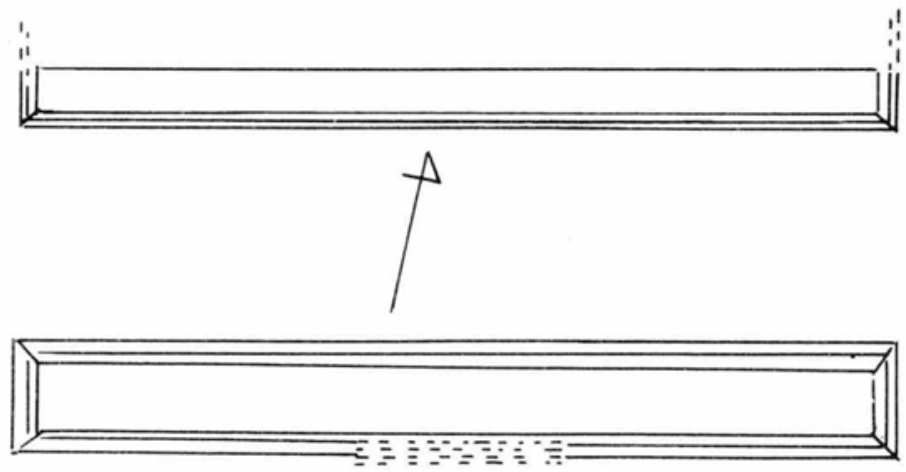

5.

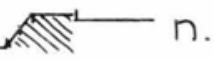

a
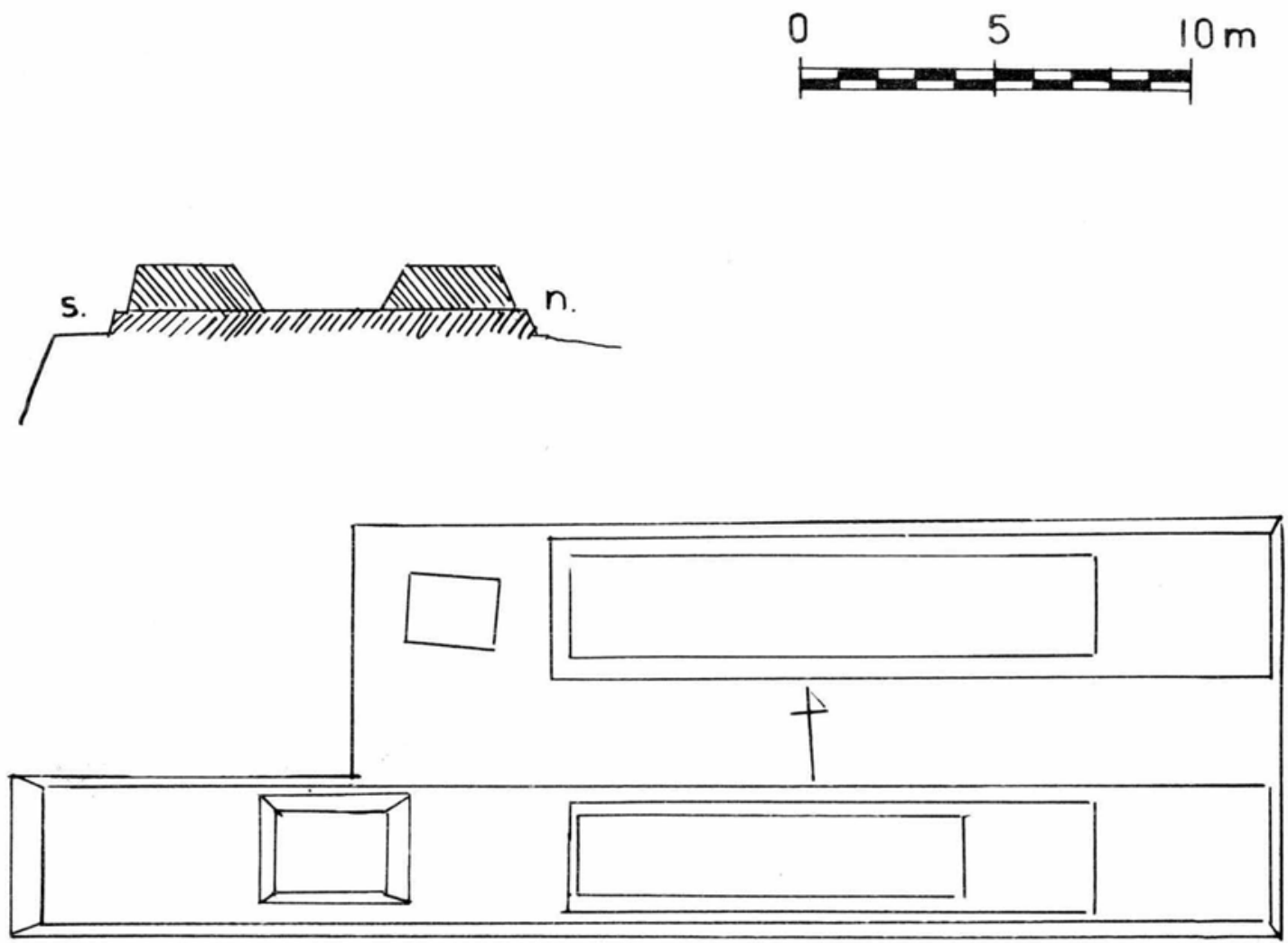

b

5. Juegos de pelota de la cultura Chalchihuites: $a-$ Hervideros; $b$ - cumbre del Cerro Afiladero. 

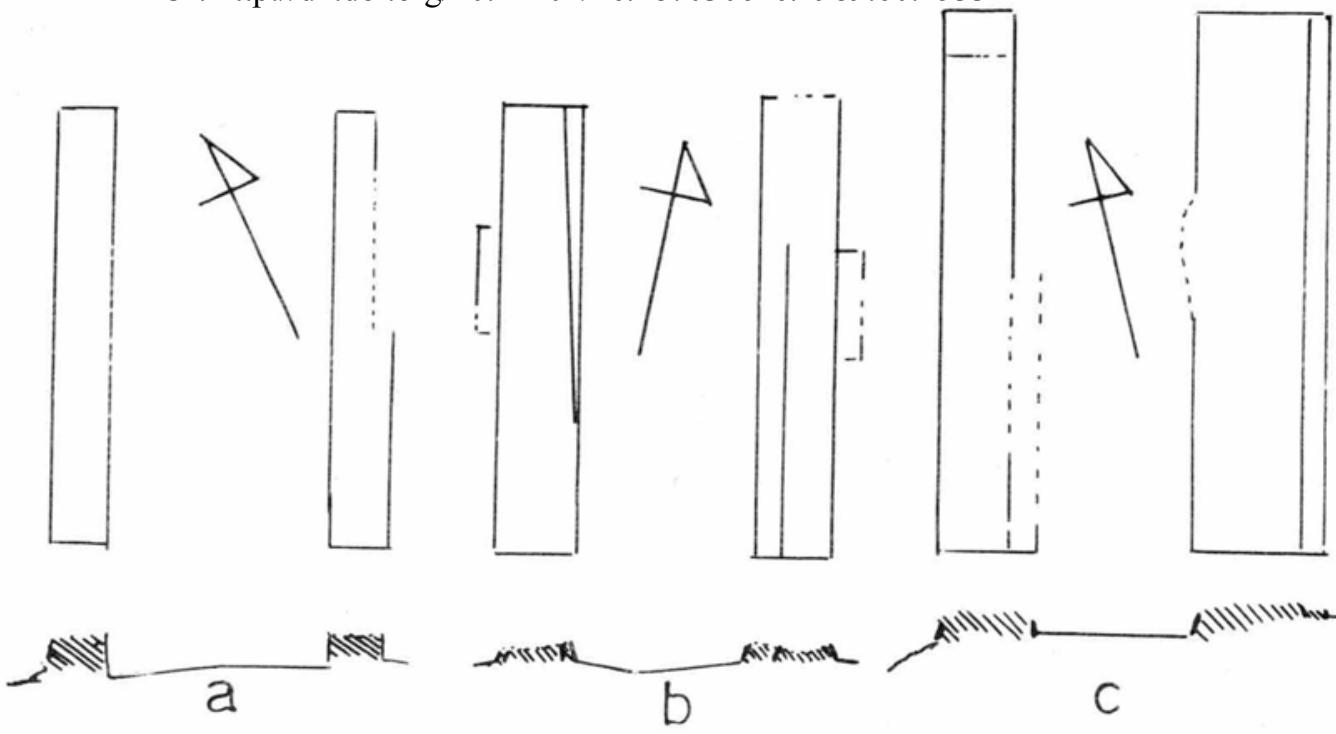

C

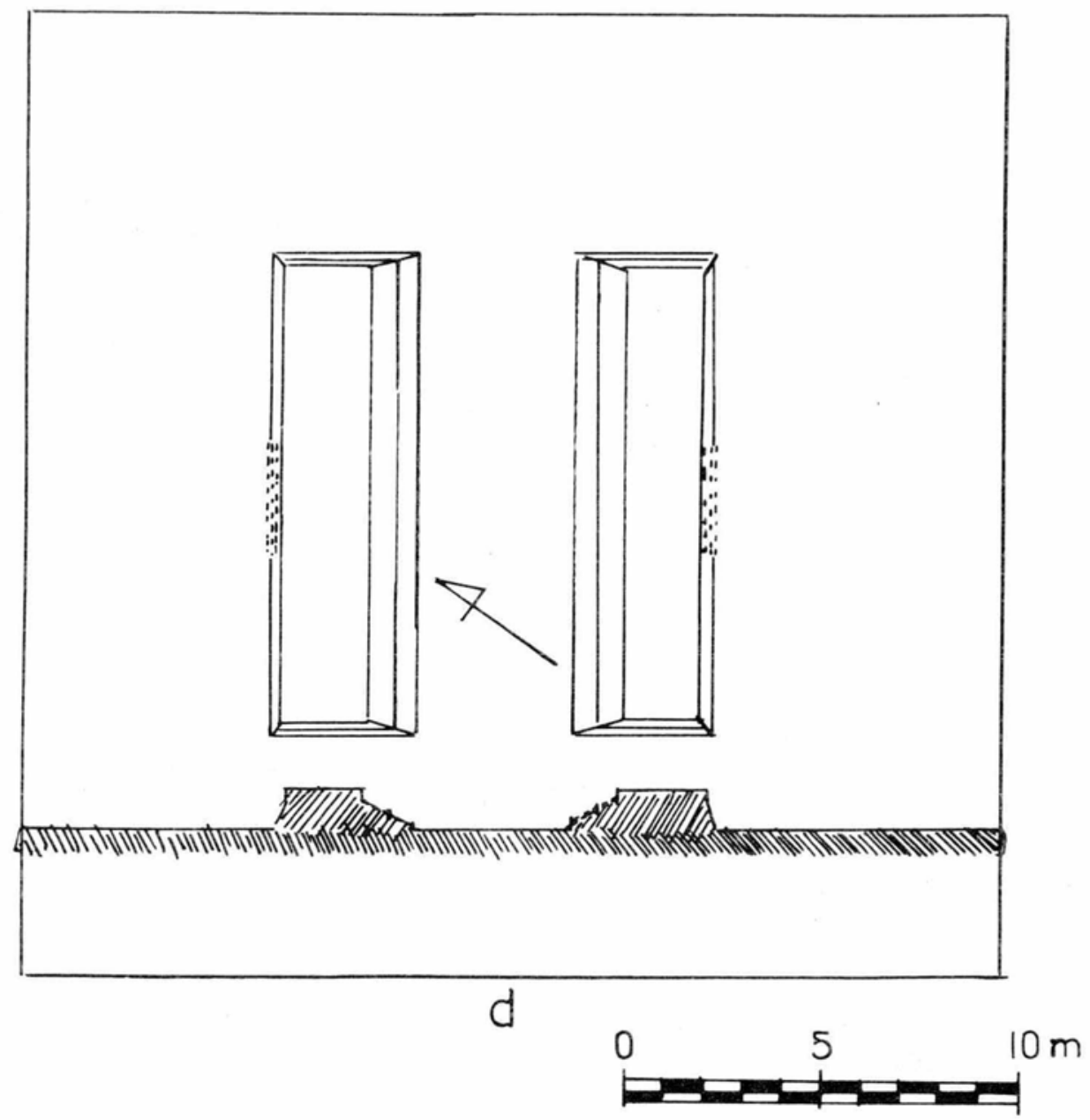

6. Juegos de pelota de la cultura Chalchihuites: a-Gualterio; b-Schroeder; c-Cerro Cruz de la Boquilla; d-loma amurallada de La Quemada. (a y b, según Ellen Abbott, op. cit., 1976: p. 44.) 
cumbre ancha y su vertiente noreste terraceada parecen haber abrigado, sobre una superficie de unas quince hectáreas, a una población de tamano y densidad apreciable y capaz de resistir ataques eventuales.

La proximidad inmediata de los recursos para la subsistencia, en particular para la agricultura, así como la abundancia de vestigios de ocupación en la cumbre, nos indican que no se trataba de uno de los numerosos refugios temporales que existieron en el territorio Chalchihuites, sino de un asentamiento permanente similar a sitios de la importancia de Schroeder-Ferrería, ya mencionado, o de Cerro Montedehuma en el Alto Súchil cerca de Gualterio en Zacatecas. Comparte con ellos la ubicación en la cumbre de una meseta que domina un valle, el tamaño de la superficie ocupada y, como veremos, ciertas características de sus espacios construidos ${ }^{19}$

Sería vano por ahora tratar de precisar el tipo de asentamiento al que corresponde Hervideros mientras ignoremos prácticamente todo acerca del patrón de asentamiento en el cual se inscribía y de las actividades a las cuales se dedicaba su población, aparte de la producción agrícola. Por su tamaño, pertenece al grupo de los asentamientos mayores de la cultura Chalchihuites, en la cual la mayor parte de los sitios son modestas aldeas que no alcanzan a cubrir una hectárea o aun media-hectárea y entre esos dos extremos se encuentran poblaciones de una a dos hectáreas de extensión. Obviamente, el tamaño no define adecuadamente la naturaleza del asentamiento, determinada ante todo por las actividades de su población, su organización interna y el papel que jugaba el sitio en su entorno regional. Al respecto, hay que tomar en consideración la necesidad que tenían los agricultores de aglomerarse para defenderse y, por lo tanto, la clasificación que se podrá intentar un día de Hervideros, y en general de todos los asentamientos Chalchihuites, tendrá que tomar en cuenta esa circunstancia peculiar de la frontera mesoamericana.

No sabemos cuấles eran las relaciones de esa población con los otros sitios de los valles circundantes pero, por lo menos, podemos constatar que río abajo, más allá de un trecho barrancoso, los campesinos aldeanos establecidos a lo largo del río Ramos se defendían a sí mismos refugiándose en el relieve accidentado, y por lo tanto se habrían mantenido fue-

19 Glen Cole considera también que se trata de un asentamiento esencialmente habitacional a juzgar por el gran número de metates, manos y utillaje lítico que observó en la superficie, así como por la naturaleza de la mayoría de las construcciones. 
ra del control militar que pudiera haber ejercido la población de Hervideros sobre su entono inmediato.

Por falta de tiempo, no pudimos levantar un plano general del sitio para analizar adecuadamente su organización intema. Después de un examen somero, fuvimos que contentarnos con un muestreo de cuatro conjuntos de construcciones que en cieria medida reflejan la variedad que hemos podido detectar entre los vestigios arquitectónicos visibles en la superficie. Antes de detenemos sobre esos ejemplos, anotaremos algunas características generales del lugar.

La cumbre tiene una planta irregular y alargada. Su superficie es cón* cava y se inclina en amplios escalones hacia el noroeste, donde la erosión ha sido la más destructiva, mientras que en otras partes el arrastre de la tierra ha recubierto los vestigios. Cinco promotorios rocosos ocupan las esquinas y el centro de la cumbre. Han sido aprovechados para adosarles terrazas sobre las cuales se levantaron construcciones, y del mismo modo han sido terraceados los flancos del cerro, en particular hacia el norte.

Los materiales de construcción que se observan en la superficie son de piedras sin labrar y bloques someramente careados. Se distinguen dos grandes grupos de construcciones según el tipo de materiales que parecen haber sido utilizados. Unas tenían paredes perecederas como de bajareque, adobe o simples palos, mientras que otras se levantaban con muros de piedra en la base y de materiales no-duraderos en la parte stuperior. De las primeras solamente persisten en la superficie las plateformas que las sostenían, mientras que de las segundas se reconocen sus cimientos formados por dos hileras de grandes piedras clavadas en el suelo y un relleno de piedras menores entre ellas. Las plataformas estaban formadas por un perimetro de grandes blogues con una altura variable según la naturaleza del terreno y la calidad de la construcción. El relleno aparentemente era de tierra llevada de otra parte y en ciertos casos recubren afloramientos de la roca. Las terrazas son amplias superficies aplanadas conformadas por un muro de contención en piedra y relleno de tierra y rocas. Sirvieron a la vez para sostener construcciones y para proteger el terreno de la erosión.

Hemos observado únicamente construcciones de plantas cuadrangulares, aurque parecen existir también pequeñas plataformas circulares anotadas por Alden Mason y otras en T reportadas por Glen Cole. En ambos casos son formas comunes en la arquitectura Chalchihuites.

Las construcciones se distribuyen sobre las terrazas o alrededor de pla- 
zas rectangulares de tamaño muy diverso, mientras que algunas más están dispersas sin orden aparente. Las plazas son patios hundidos, rodeados total o parcialmente de banquetas que soportan las construcciones. Algunos de esos patios están aislados y en cambio otros se agrupan. La plaza mayor del sitio se encuentra en el centro de la cumbre. Desgraciadamente, ha quedado en gran parte sepultada y para levantar el plano de su contorno, lo mismo que el de las construcciones reunidas alrededor de ella, se hubiera necesitado hacer excavaciones fuera del alcance de nuestra breve estancia.

En diversas partes de la cumbre se aprecian todavía trechos de calzadas delimitadas por dos hileras de grandes piedras que detenían el relleno de tierra. Anchos escalones franquean las irregularidades del terreno. Las calzadas mejor conservadas son la que asciende al promontorio rocoso de la extremidad noreste de la cumbre, la que lleva al conjunto sur - del cual hablaremos- y las que escalan los promontorios que dominan dicho conjunto. Calzadas similares se encuentran entre los grupos de construcciones de otros numerosos sitios Chalchihuites, como Cerro Montedehuma, Alta Vista o La Quemada.

A primera vista, el crecimiento del sitio parece haber seguido la norma imperante en los asentamientos Chalchihuites que consiste en el agregado de conjuntos enteros de habitaciones en lugar de casas aisladas. Esos conjuntos corresponderían a unidades sociales básicas más amplias que las familias nucleares. ${ }^{20}$

Esos conjuntos no son uniformes sino que varían en dimensiones, complejidad y refinamiento de sus construcciones. Sin excavaciones adecuadas, no podemos determinar si tales variaciones se deben a diferencias entre los pobladores o a funciones distintas de las construcciones. En todo caso, esas diferencias parecen reflejar una organización social compleja. De ese modo, el asentamiento no parece haberse limitado al agregado de grupos aldeanos para poder defenderse adecuadamente, como es el caso de numerosos sitios Chalchihuites, sino de una población con un mayor grado de diferenciación social y de urbanización.

El primer conjunto que analizaremos es el más simple (figura 2). Se encuentra al borde de la cumbre. Se levanta sobre una superficie apla-

20 J. Charles Kelley and Ellen Abbott, Op. cit., 1966; Marie-Areti Hers. "Las Salas de las Columnas en La Quemada", en Arqueología del Norte y Occidente de México; homenaje a J. Charles Kelley (Zacatecas, 1986), Instituto de Investigaciones Antropológicas, Universidad Nacional Autónoma de México, México (en prensa). 
nada bastante ancha, bordeada por muros de contención que afloran apenas en la superficie actual. Está compuesto por dos construcciones. La mejor conservada es una plataforma baja de planta rectangular alargada $(12.5 \mathrm{~m} \times 5.7 \mathrm{~m})$. Actualmente su altura es casi nula en la fachada, mientras que en la parte trasera presenta dos escalones para alcanzar la desnivelación del terreno y para protegerla de la erosión, más destructiva al borde de la cumbre. Parece haber soportado dos cuartos contiguos. El de la mitad sur se reconoce por sus cimientos de piedra que encierra un espacio interior modesto $(3 \mathrm{~m} \times 5 \mathrm{~m})$. El de la mitad norte no dejó vestigios visibles pero, a juzgar por el espacio dejado libre sobre la plataforma, podemos suponer que se trataba de una construcción en materiales perecederos sobre toda su elevación, de tamaño similar a la anterior. En el frente, el espacio libre de un metro de ancho podría indicar la presencia de algún corredor encima del cual se prolongaba el techo de los cuartos. Al sureste de la plataforma, subsisten los restos muy destruidos de otra construcción cuyo contomo es de dimensiones similares a cada uno de los cuartos que se elevaban sobre la plataforma.

Ese conjunto parece corresponder a la vivienda de una familia nuclear con su cuarto de habitación, su cocina adjunta, su corredor o pórtico en la fachada, eventualmente su granero (la pequeña plataforma destruida) y su espacio abierto enfrente. Esas construcciones suelen agruparse y formar plazas total o parcialmente cerradas.

Tal es el caso del segundo conjunto (figura $2 \mathrm{~b}$ ) en donde se reconocen las plataformas bajas soportando pequeños cuartos contiguos, unos con cimientos en piedra y otros en materiales perecederos y el corredor enfrente. Las construcciones se alinean para encerrar dos pequeñas plazas cuyo ordenamiento está perturbado por los afloramientos de la roca que fueron aprovechados para el relleno de las plataformas y por la leve vertiente hacia el este. Restos de una construcción muy destruida ocupan el centro de la plaza del sur y corresponden probablemente a otro momento de la ocupación del lugar.

El conjunto de esa docena de cuartos contíguos alineados y con un corredor en la fachada es muy similar a los que conforman las aldeas del río Ramos, ilustradas por Richard Brooks con croquis simplificados y breves descripciones. Esos agrupamientos de casas modestas conforman la mayoría de los vestigios en Hervideros y de los otros asentamientos importantes con los cuales hemos comparado el sitio. Por la similitud con las aldeas podemos suponer que se trata de las habitaciones de la base campesina de la población. 
Los conjuntos que destacan por sus dimensiones y la calidad de sus construcciones siguen el modelo básico de plataformas soportando cuartos contiguos provistos de un corredor en la fachada. De ese modo y sin excavaciones adecuadas no se puede determinar si corresponden a las habitaciones de ciertos grupos de pobladores $O$ a actividades particulares de orden político o religioso, por ejemplo.

El tercer ejemplo que detallaremos es particularmente representativo de esa ambigüedad (figura 3b). La simplicidad de su plano lo acerca a los conjuntos habitacionales anteriores mientras que sus dimensiones, el cuidado puesto en su construcción y la cercanía de la plaza mayor del sitio lo aproximan al conjunto que Alden Mason y Glen Cole han reportado como espacio ceremonial, y del cual nos ocuparemos después.

El tercer conjunto se encuentra al centro de la cumbre, al sur del segundo, al este del primero y al noreste de la plaza mayor del sitio. Se adosa a un promontorio rocoso que ha sido terraceado en su flanco sur. El espacio es más estrictamente ordenado por banquetas perpendiculares que bordean dos patios cuadrados contiguos de $22 \mathrm{~m}$ de lado cada uno. Los lados sur y oeste están parcialmente sepultados por el arrastre del terreno que va de suroeste a noreste.

Un solo largo basamento cierra el lado norte de ambos patios $(37 \mathrm{~m}$ $\times 7 \mathrm{~m}$ ) con gradas verticales cuyo número varía según el declive del terreno sobre el cual ha sido eregido. El promontorio rocoso no ha sido completamente recubierto y aflora, dividiendo en dos el basamentos y prolongándose hacia el sur en medio de la banqueta perpendicular que separa los dos patios. Frente al patio del este, el gran basamento se eleva $1.5 \mathrm{~m}$. sobre el suelo actual y su altura original puede haber sido de unos $2 \mathrm{~m}$. No se ven vestigios de una escalinata para franquear esa desnivelación y aparentemente se accedía allí por la escalera en el rincón oeste de la plaza. El pasillo que corre a lo largo de su fachada es bastante ancho $(2 \mathrm{~m})$ y se prolonga sobre el lado este. Da acceso a un cuarto alargado $(16 \mathrm{~m} \times 4.2 \mathrm{~m})$ que quizás estaba dividido originalmente en dos, como lo sugiere una desnivelación transversal pero cuyo interior ha sido considerablemente perturbado por el ganado y algunos árboles. Al este, el patio está delimitado por una hilera de grandes rocas al borde de una desnivelación terraceada. La banqueta sur apenas se distingue en la superficie y sobre la del oeste no subsisten vestigios de las construcciones, que eran probablemente de materiales perecederos. En medio del espacio abierto, se reconoce el contorno de un altar saqueado, cuadrado, de unos $5 \mathrm{~m}$ de lado y muy bajo. 
En el patio del oeste, en el cual el acarreo hidráulico arrastró aún más tierra suelta que en el contiguo, el gran basamento tiene una altura actual de $1 \mathrm{~m}$. Sostiene dos cuartos, uno al lado del otro, de dimensiones tan modestas como los de los dos primeros conjuntos descritos. Esos cuartos están rodeados por un pasillo de $1 \mathrm{~m}$ de ancho que corre en la fachada, en el lado oeste y en la parte trasera. Uno de ellos ha sido saqueado y del talud de tierra que rodeaba el pozo hemos rescatado una sonaja de cobre y fragmentos de huesos humanos, lo que nos indica que el terraplén del basamento, como es común, sirvió para sepultar a los difuntos debajo del piso de la construcción. Al oeste del patio, solamente se adivina el contorno de una construcción y hacia el sur el límite quedó totalmente bajo tierra. De existir aquí también un altar central, estaría sepultado.

La parte mejor conservada del sitio se encuentra en el extremo sur, en el nivel más alto, por lo que no fue sepultado, y estuvo protegido de la erosión al este $\mathrm{y}$ al oeste por promontorios rocosos, $\mathrm{y}$ al sur y al norte por terrazas artificiales (figura 4). Reúne los vestigios arquitectónicos más imponentes en la superficie. Son las ruinas que llamaron particularmente la atención de nuestros predecesores. Se accede a ellas por la ancha calzada ya mencionada que recorre la vertiente norte terraceada. Al este, se levanta la cresta más alta de la cumbre, a la cual conducía otra calzada que serpentea desde la plaza sureste del conjunto. Arriba, se extienden varios empedrados entre las grandes rocas, desde donde se disfruta del mejor punto de observación sobre los valles circundantes y sobre la cumbre. Al oeste, la masa rocosa es menos alta y más pequeña. En el punto más elevado, se observa un pequeño empedrado de $3 \mathrm{~m}$ de lado. El estribo entre las dos crestas se extiende sobre media hectárea y queda subdividido en cuatro plazas ubicadas en dos niveles.

El nivel superior oriental está bordeado al este por el muro de contención de la primera terraza adosada a la cresta rocosa. Una plataforma bastante destruida se extiende perpendicularmente al muro de contención citado y divide así el nivel en dos plazas contiguas. Ambas están bordeadas al oeste por una típica plataforma que sostiene dos cuartos contiguos y con un pasillo en la fachada y a lo largo de una cara lateral. Esas plataformas tienen una altura casi nula sobre el piso actual de sus respectivas plazas, parcialmente sepultadas por materiales arrastrados desde la cresta al este. Pero en su parte trasera, esos basamentos alcanzan una altura de más de $2 \mathrm{~m}$ sobre el piso del nivel inferior occidental. La plaza al norte comprende en el centro un pequeño altar cuadrado 
que apenas se distingue en la supericie, y en el límite note, un erinicio aislado muy perturbado por un saqueo. La plaza sur carece ararentemente de altar y está cerrada al sur por un basamento que se adosa a la roca y se prolonga hacia el oese más allá del limite del nivel superior.

El nivel inferior del oeste compreade las construcciones más elaboradas que hemos podido observar en la supericie del sitio. El patio hundido del noroeste forma un cuadrado de $22 \mathrm{~m} \times 17 \mathrm{~m}$. Está dominado por un amplio basamento adosado a la cresta rocosa del oeste y con graw das verticales hacia adelonte partalcanzan una altura actual de $2 \mathrm{~m}$ y originalmente quizás de unos $3 \mathrm{~m}$ me la plaza azolvada. En medio de la fachada se empotra una esculinda que lleva a la parte atra que mide $16 \mathrm{~m} \times 7 \mathrm{~m}$. El corredor de frente es ancho $(2 \mathrm{~m})$. Atrás de ell los vestigios son confusos y no se puede definir claramente si se trate de cimicntos de un solo cuarto amplio de varios contiguos.

A lo largo de la banqueta norte del paio corre un pasillo también de $2 \mathrm{~m}$ de ancho, atrás del cual se distinguen dos edificios aislados y una escalinata que lleva hacia abajo. Las banquetas sur y este están mal conservadas y las construcciones quo sastaian no se reconocen con prem cisión. Unas son plataformas bajas y otras son cimientos de muro en piedra. Se advierte que el patio así fomado no es simétrico. La plaza parece haber sido alargada en su otigen, y posteriomente su espacio habría sido invadido parcialmente por la banqueta del este, que no llegó sin embargo a cerrar completamente el patio. Al centro, el altar cuadra do apenas sobresale, y también ha sido saqueado.

La plaza al suroeste está dominada por un amplio basamento similat al del patio noroeste, pero es un poeo menor y está menos bien conservado. Frente a la escalinata empotrada en su fachada se extiende per pendicularmente un juego de pelota con cabeceras abiertas. El cuerpo lateral norte se adosa a la banqueta que separa las dos plazas del nivel occidental. El cuerpo sur presenta en medio de su cara trasera una es calinata muy arruinada. El pasillo central mide $20.5 \mathrm{~m} \times 4.8 \mathrm{~m}$; el cuerpo lateral norte tiene $12 \mathrm{~m}$ de ancho en la base y $0.9 \mathrm{~m}$ arriba, mientras que el del sur tiene $2.6 \mathrm{~m}$ en la base y $1.5 \mathrm{~m}$ arriba. La altura conservada de ambos es de $0.8 \mathrm{~m}$ y la orientación es de $78^{\circ}$. Las caras frontales y laterales de los dos cuerpos presentan sobre toda su altura un talud muy destruido.

Ese juego de pelota es el más grande de los ocho del mismo tipo com nocidos por ahora para la cultura Chalchihuites, sin contar con el mayor 
de La Quemada, que tiene cabeceras, ${ }^{21}$ ni con el del Teúl de González Ortega, en el extremo suroeste de Zacatecas, de elevación mucho mayor.

Los ocho juegos de pelota son, aparte del de Hervideros, los dos reportados por Alden Mason en la región de Sotolitos en la parte alta de 1a Sierra Madre Occidental, ${ }^{22}$ el del sitio de Schroeder-Ferrería excavado por J. Charles Kelley, ${ }^{23}$ el de Gualterio excavado por Ellen Abbott Kelley, ${ }^{24}$ el que encontró el Proyecto Sierra del Nayar de la Misión Arqueológica Belga en la cumbre del cerro Afiladero (sitio RSV-III) en el Alto Chapalagana, ${ }^{25}$ y los que detecté en el sitio del Cerro Cruz de la Boquilla cerca de Sombrerete y en la loma amurallada de La Quemada. ${ }^{28}$

Todos esos juegos de pelota tienen en común una planta muy simple conformada por dos plataformas estrechas y paralelas. Sus dimensiones son muy reducidas, tanto para la avenida central (el ancho oscila entre 4 y $5 \mathrm{~m}$ y el largo entre 10.5 y $13 \mathrm{~m}$, salvo el de Hervideros que alcanza los $20.5 \mathrm{~m}$ ) como para las banquetas laterales (entre 1.2 y $2 \mathrm{~m}$ de ancho y con una altura conservada no mayor de $1 \mathrm{~m}$ ). Por sus dimensiones tan reducidas, es dudoso que las banquetas hayan sostenido alguna estructura sobre la que hubiese podido rebotar la pelota o donde se hubieran colocado los espectadores. Parecen haber sido destinadas solamente a demarcar un espacio. Este, por su exiguiidad, no era adecuado para un juego entre equipos, sino más bien entre individuos.

Se inscriben en el tipo IX de juegos abiertos con talud subvertical, de la tipología establecida por Eric Taladoire. ${ }^{27}$ Las fechas disponibles para los dos casos de juegos excavados son la fase Canutillo (100-500 d. C) para el juego de Gualterio y las fases Ayala y Las Joyas (550-1000 d. C) para el juego de Schroeder. Como veremos más adelante, es probable que ese juego de pelota de Hervideros, como la mayoría de las construcciones visibles en su superficie, corresponda a su última etapa

21 Román López García y Laura Castañeda. Informe de los trabajos realizados en la Quemada en 1979-1980 (Archivo Técnico, C/311.41 (Z 41-1)/1), Departamento de Monumentos Prehispánicos, Instituto Nacional de Antropolgía e Historia, México, ms.

22 Allden Mason, Op. cit., p. 1422, fíg. 4c.

23 J. Charles Kelley, Op. cit., 1971.

24 Ellen Abbott Kelley, Op. cit., 1976.

25 Claudine Levie-Deltour, ed., Op. cit., en prensa: vol. 1, sitio RSV-III.

26 Marie-Areti Hers, en Claudine Deltour Levie, ed., Op. cit., en preparación: vol. II.

27 Eric Taladoire. Les Terrains de jeu de balle (Mésoamérique et Sud-Ouest des Etats-Unis) (Etudes Mésoaméricaines, série II-4), Mission Archéologique et Ethnologique Française au Mexique, Mexico, 1981. 
de ocupación, posterior a 900/1000. Por lo tanto, esa forma de cancha habría perdurado a lo largo de toda la evolución de la cultura Chalchihuites.

Esos juegos de pelota se singularizan también por encontrarse en poblaciones de tamaño muy variable: en el sitio principal de La Quemada, en los sitios mayores como Hervideros o Schroeder, en los de tamaño mediano como el Cerro Cruz de la Boquilla, en modestas aldeas como las de la región de Sotolitos y en un simple refugio temporal como la cumbre del Afiladero.

Lo más notable, sin embargo, es su estrecha relación con los momentos más dramáticos de la guerra, evidenciada por su ubicación misma en lugares defensivos. Los casos más evidentes al respecto son los de La Quemada y de la cumbre del Afiladero. El primero se encuentra en la loma amurallada en donde los campesinos de los alrededores acudían a refugiarse. El segundo se ubica en la cumbre de una cresta rocosa rodeada en tres lados por precipicios impresionantes, en particular hacia el sur, donde se trata de una pared vertical vertiginosa. Allí podían replegarse momentáneamente los pobladores de los alrededores detrás de una serie de muros que controlaban el paso desde el único lado accesible. En ambos casos el juego se levanta sobre una amplia explanada.

Alden Mason no precisa la ubicación de los sitios en los cuales encontró los dos juegos que menciona ni si se inscriben en algún dispositivo particular. Ignoramos por lo tanto si se trata de sitios defensivos, como es el caso de la mayoría de los asentamientos que estudió, y si los juegos se encuentran o no sobre una explanada o en medio de una plaza. De los otros tres juegos, el de Schroeder y el del Cerro Cruz de la Boquilla no presentan ningún dispositivo particular, en medio de conjuntos habitacionales con sus respectivos patios hundidos, mientras que el de Gualterio se encuentra al final de una larga plaza, rodeada por conjuntos de este tipo.

E1 caso de Hervideros se acerca a los dos primeros mencionados, puesto que se ubica en el punto más alto y mejor protegido del sitio. No se levanta sin embargo sobre una explanada sino que, como en Gualterio, se encuentra en una plaza. Las construcciones que podrían haber estado relacionadas con él son los aposentos que se levantaban sobre el gran basamento al oeste y sobre la banqueta a la que se adosa el cuerpo norte del juego. Obviamente, sin excavaciones, no podemos ni confirmar ni precisar esa relación. Es curioso al respecto que el basamento que cierra la plaza del juego de pelota al este le daba la espalda ya que, como 
vimos, los cuartos que sostenía se abrían hacia el otro lado y que el pasillo que rodeaba los aposentos no se prolongaba hacia atrás para acoger a los espectadores de los juegos.

La relación espacial de esa serie de juegos de pelota con la guerra y las dimensiones apropiadas para enfrentamientos individuales evocan inevitablemente la idea del juego de pelota como sustituto de la guerra para resolver conflictos bélicos. ${ }^{28}$ Tal función para el juego de pelota es congruente además con el belicismo exacerbado que ha imprimido un sello muy particular a la cultura Chalchihuites.

Recordemos al respecto la presencia de autênticos izompantlis entre esos fronterizos aguerridos durante la época clåsica, presencia que, junto a otros elementos, me han llevado a identificar a esos mesoamericanos norteños con los tolteca-chichimeca que según las fuentes históricas llegaron al final de su migración desde el norte a fundar el imperio tolteca. ${ }^{29}$ En esas circunstancias, la asociación diel juego de pelota con el tzompantli que se advierte en Tula, en Chichể-Itzá y en Tenochtitlan tendría su origen en los confines norteños y llevaría a distinguirla claramente la asociación más ampliamente difundida del juego con la simple decapitación.

En tiempos coloniales, los acaxees de la serrania de Topia, al noroeste de Hervideros, habían llegado a un alto grado de ritualización de la guerra y, como sus antecesores Chalchihuites, practicaban la guerra flo rida. Además, organizaban partidos de juego de pelota entre pueblos, durante los cuales apostaban todas sus riquezas. Tal costumbre, junto con los sacrificios humanos que motivaban las guerras floridas, era otra via más para encauzar ritualmente los conflictos bélicos. ${ }^{30}$

De todas las construcciones de Hervideros que hemos detallado, el juego de pelota es la única cuya función ceremonial es indudable. Para las demás, podemos constatar que la casa campesina común ha servido de modelo aun en el conjunto más elaborado. Solamente, un programa amplio de excavaciones podría determinar la naturaleza de esas variaciones en las dimensiones y la calidad de la construcción y precisarnos si, por ejemplo, eran moradas de dirigentes o moradas de los dioses. ${ }^{31}$

28 Eric Taladoire. Ibid.." pp. 541-542.

29 Marie-Areti Hers. Op. cit., 1989.

30 Eric Taladoire retoma la información del padre Alegre: Op. cit, 1981: p. 541. Sobre los acaxees, en general, ver Ralph L. Beals The Acaxee, a Mountain Tribe of Durango and Sinaloa (Ibero-Americana, 6), University of California, Berkeley, 1933.

$31 \mathrm{La}$ presencia actualmente de un gran número de fragmentos de metates entre 
En estas últimas, resalta ante todo la ausencia de basamentos más altos que anchos como son las pirámides, que en otras regiones mesoamericanas aislaban los templos por encima del espacio de la vida cotidiana. En la arquitectura ceremonial Chalchihuites, esa forma ha sido muy poco utilizada y las escasas pirámides que han sido reportadas son de dimensiones muy modestas, mientras que en un sitio tan importante como el Cerro Montedehuma en el Alto Súchil no se reconoce en la superficie ningún basamento con una elevación suficiente como para considerarlo piramidal. Los templos han de haber sido en muchas ocasiones construcciones modestas sobre simples plataformas. Se conocen casos de vestigios similares a los de las casas comunes que revelaron ser templos por el mobiliario que se encontró asociado a ellas. Así, por ejemplo, en el Cerro del Huistle ya citado para el Alto Chapalagana, esculturas de un protochac mool y empalizadas con cráneos humanos en su interior y a sus lados permitieron determinar su función ceremonial y pública.

En el sitio de Schroeder-Ferrería, en el valle de Guadiana, que es el sitio conocido más cercano a Hervideros, se reporta la presencia de una "pirámide" pero, en realidad, se trata de un ancho basamento que encierra la cumbre rocosa y que sostiene un patio hundido recortado en la roca y rodeado por banquetas sobre las cuales se levantaban diversas construcciones. En Hervideros, parece que tampoco se utilizó la pirámide para realzar los templos, aunque este punto tendría que ser confirmado por trabajos posteriores más sistemáticos. ${ }^{32}$

En realidad, la construcción ceremonial más característica de la cultura Chalchihuites es la amplia sala que, en los sitios mayores, revistió la forma singular de un claustro conformado por un espacio central cuadrangular abierto similar a un impluvium, rodeado por un corredor aporticado que no lleva a ninguna estancia, a veces con un pórtico en la fachada que se prolonga en ambos lados conformando así una planta en $T$.

En Durango, aún no se ha reportado la presencia de tal claustro

las ruinas del conjunto IV -marcados con un * en el plano-y sobre la cresta rocosa del sureste no demuestra en sí el uso habitacional de esos espacios porque no podemos asegurar que se encuentran in situ y que no fueron agrupados aquí por visitantes ocasionales, después del abandono del sitio. Esa duda es particularmente válida para los cuatro fragmentos que se encuentran en la cancha del juego de pelota.

32 En su informe ya citado, Glen Cole menciona que al pie de la colina se encuentra una "estructura piramidal o plataforma" que no hemos tenido la oportunidad de observar para precisar de qué se trata. 
(llamado comúnmente sala de las columnas aunque no sea una sala hipóstila). En el sitio de Schroeder-Ferrería, el patio hundido mencionado, encima de un basamento que domina todo el sitio, representaba probablemente el espacio ceremonial de mayor trascendencia de la población. Por su forma de reunir a un grupo importante de personas, aislarlas de los demás y al mismo tiempo dejarles un espacio al aire libre se acerca en alguna medida a la sala-claustro, en la cual podía circular un número apreciable de personas que quedaban fuera de la vista de los demás pero que permanecían bajo los rayos del sol.

En Hervideros, no hemos detectado tampoco la presencia de una salaclaustro. Tal ausencia puede ser solamente aparente ya que, como señalamos, lo que parece haber sido la plaza mayor del sitio en donde podría haberse levantado tal edificio, ha quedado en gran parte sepultada. Por otra parte, el conjunto IV, ubicado sobre la parte más alta del cerro y realzado del lado de su acceso por las terrazas y la calzada, presenta similitudes con el caso de Schroeder-Ferrería, dominado por un patio hundido encima de un alto basamento. El conjunto IV de Hervideros se diferencia, sin embargo, por reunir cuatro plazas y no una sola. En ambos casos, queda esa ambigiedad entre un conjunto que por su ubicación y el cuidado puesto en su construcción parece haber sido dedicado a actividades eminentemente ceremoniales, pero que formalmente no se diferencia fundamentalmente de las construcciones comunes.

Hasta ahora, la planta característica en Hervideros de un basamento sosteniendo dos cuartos contiguos y con un pasillo en el frente, no ha sido reportada más que en las aldeas durangueñas atribuidas a la cultura Loma San Gabriel, aunque en el Cerro Cruz de la Boquilla, junto a Sombrerete, hemos encontrado algo similar. Son plataformas que sostienen dos cuartitos y que presentan en la fachada un pasillo más largo que el ancho de la plataforma, lo que le da una planta en T. Como hemos visto, el origen de esa forma arquitectónica en la sencilla casa campesina da un carácter aparentemente profano a las construcciones más elaboradas de Hervideros e impide distinguir claramente los espacios ceremoniales y los privados.

Por su ubicación estratégica, por los tipos de construcciones que se observan en la superficie, por sus patios hundidos y su juego de pelota, por sus calzadas y terrazas, así como por sus materiales cerámicos y líticos, Hervideros pertenece a la cultura Chalchihuites, con ciertas particularidades locales anotadas, que se podrán apreciar pertinentemente cuando se disponga de más descripciones detalladas y planos precisos de 
sitios representativos de las diversas zonas y épocas de dicha cultura. La ubicación espacio-temporal de los vestigios arquitectónicos de Hervideros hace más compleja esa distinción de variantes regionales por el hecho de que muchas de las ruinas aparentes en la superficie pueden datar de una época en la que la mayoría de los sitios mejor conocidos de la parte zacatecana y jalisciense del territorio Chalchihuites habian sido abandonados.

Como anotamos, en efecto, la ocupación de Hervideros se prolongó más allá de 900 , cuando ocurrió el primer colapso de la frontera mesoamericana y cuando la región durangueña quedó comunicada con lo demás de Mesoamérica solamente a través de la región que corresponde al actual estado de Sinaloa, durante el llamado Horizonte Aztatlán.

El sitio de Schroeder-Ferrería es el único excavado en el cual la ocupación perduró, como en Hervideros, más allá de 900. Desgraciadamente, no se han detectado alli las construcciones que corresponderían a la ocupación del lugar en el Horizonte Aztatlán. ${ }^{23}$ Por lo tanto, no tenemos elementos de comparación adecuados para interpretar las peculiaridades que hemos anotado en Hervideros y que podrían ser espaciales o diacrónicas.

El sitio de Schroeder-Ferreria y el valle de Guadiana en general se comunicaba por el curso de los ríos Mezquital-San Pedro y Acaponeta con las áreas de Mazatlán, de Chametla, de Marismas Nacionales y de Amapa, en donde se han encontrado vestigios de una ocupación mesoamericana tan antigua como la colonización Chalchihuites de la vertiente oriental de la Sierra Madre Occidental, mientras que Hervideros se relacionaba más directamente con áreas más septentrionales de Sinaloa cuya ocupación mesoamericana parece haber empezado más tarde, precisamente cuando floreció el horizonte Aztatlán. ${ }^{34}$

${ }^{33}$ La hipótesis de J. Charles Kelley al respecto es que después de la fase Las Joyas, la ocupación del sitio se redujo a peregrinaciones eventuales en un antiguo santuario.

${ }^{4}$ Jaime $R$. Ganot y Alejandro F. Peshard. "La cultura Aztatlán: frontera del Occidente y Norte de Mesoamérica en el Postclásico", en Validez teórica del concepto de Mesoamérica; XIX Mesa Redonda (Querétaro, 1985), Sociedad Mexicana de Antropología, México, en prensa, y J. Charles Kelley. "Hypothetical Functioning of the Major Postclassic Trade System of West and Northwest Mexico", en El Occidente de México, XVIII Mesa Redonda (Taxco, 1983), Sociedad Mexicana de Antropología, México, en prensa; Carl Sauer y Donald Brand Aztatlán: Prehistoric Mexican Frontier on the Pacific Coast (Ibero-Americana, 1), University of California Press, Berkeley, 1932; Isabel Kelly. Excavations at Chametla (IberoAmericana, 14), University of California Press, Berkeley, 1938 y Excavations at 
Recordemos, al respecto, que para el estado de Durango no se dispone aún de los datos adecuados para determinar las fechas iniciales de la ocupación mesoamericana a lo largo de la vertiente este de la Sierra Madre, y que el siglo VI que aparece comúnmente en los cuadros cronológicos ha de considerarse aún como tentativo. Existe la posibilidad de un inicio anterior, por lo menos en ciertas partes, como lo sugiere la presencia de figurillas de aspecto "chinesco" en colecciones de los museos de Durango y de México. Las estrechas relaciones entre las culturas prehispánicas que han florecido en ambas vertientes de la Sierra Madre Occidental han sido anotadas desde hace tiempo, pero siguen aún muy escasamente documentadas..$^{35}$ Han de haber jugado un papel importante, todavía no definido, en la extensión de la frontera mesoamericana hasta el río Fuerte durante el llamado Horizonte Aztatlán.

El sitio de Hervideros ocupa una posición privilegiada en la red de caminos que han de haber cruzado la Sierra Madre Occidental. Se encuentra en efecto en un cruce importante. De sur a norte, los valles de los ríos Santiago y Tepehuanes se encuentran en la via natural que lleva desde el valle de Guadiana y el antiguo lago de Papasquiaro hasta la serranía de Topia, y de allí hasta las antiguas provincias de Sinaloa y de Culiacán. Es el camino que tomó, por ejemplo, el obispo Mota y Escobar para dirigirse de Durango a Topia y de Culiacán a Topia. ${ }^{36}$ Por otra parte, de oriente a poniente, remontando el río Nazas y su afluente el río Ramos, se pasa del altiplano árido hasta la zona de Hervideros y de allí quedan relativamente cercanas las fuentes de los ríos San Lorenzo y Culiacán, ejes vitales de regiones sinaloenses densamente pobladas a la llegada de los españoles y en el horizonte Aztatlán anterior.

Tenemos un testimonio directo de esa red de veredas que unían regiones geográficamente tan distintas. Se trata de tres orejeras en cobre similares a la que reportó e ilustró Alden Mason para Hervideros: una fue hallada en Guasave sobre el río Sinaloa, la otra en la serranía de

Culiacán (Ibero-Americana, 25), University of California Press, Berkeley, 1945; Gordon Eckholm. Excavations at Guasave, Sinaloa, México (Anthropological Papers of the American Museum of Natural History, vol. 38), New York, 1942.

35 Isabel Kelly. $O p$. cit, 1938: $p_{\text {. }} 42$ note 2; J. Charles Kelley and Howard Winters. "A Revision of the Archaeological Sequence in Sinaloa", American Antiquity, 25, pp. 547-561, Washington, 1960.

36 D Alonso de la Mota y Escobar. Descripción geográfica de los Reinos de Nueva Galicia, Nueva Vizcaya y Nuevo León (con una introducción de Joaquín Ramírez Cabañas), Editorial Pedro Robredo, México, 1940: pp. 112-115 y 202207. 
Topia y la última en el cañón del Molino, cerca de Guatimapé, en la región del lago de Papasquiaro. ${ }^{37}$

Esa breve visita que hemos hecho a Hervideros, treinta años después de la prospección realizada bajo la dirección de J. Charles Kelley y cincuenta años después del recorrido pionero de Alden Mason, nos ha llevado más bien a plantear interrogantes que a proponer soluciones. Nos permitió, sin embargo, confirmar la importancia que le había atribuido Alden Mason. En efecto, las nuevas informaciones que hemos ofrecido aquí nos permitieron comparar Hervideros con los sitios mayores conocidos hasta ahora en los confines septentrionales de Mesoamérica. Quizás se trate del último de esos centros rectores de la cultura Chalchihuites antes de penetrar, más allá del límite actual entre Durango y Chihuahua, en el área cultural del Suroeste. Cuando los estudios mesoamericanistas en Durango salgan de su larga letargia, un estudio sistemático de Hervideros se impondrá prioritariamente para entender mejor la expansión de la civilización mesoamericana en el gran Norte a la vez que la peculiar naturaleza de lo que se llama confusamente Horizonte Aztatlán.

37 Jaime Ganot R. y Alejandro Peshard F., Op. cit., en prensa: lám, 3. 